www.jmscr.igmpublication.org

Impact Factor 5.84

Index Copernicus Value: 83.27

ISSN (e)-2347-176x ISSN (p) 2455-0450

crossref DOI: _https://dx.doi.org/10.18535/jmscr/v5i8.77

Journal Of Medical Science And Clinical Research

IGM Publication

An Official Publication of IGM Publication

\title{
Treatment of limb length dyscripancy following surgeries around hip in Tertiary Care Institute in India
}

\author{
Authors \\ Dr Neetin P Mahajan, Dr E. D. Pawar, Dr Farookh Wadia, Dr Ujjwal Ramteke \\ Dr Ved Ashish Ravesh, Dr Prasannakumar G S, Dr Ishan Gajbe \\ Department of Orthopaedics, Grant Govt Medical College, Sir J J Group of Hospitals, Byculla, Mumbai \\ Corresponding Author \\ Dr Neetin Pralhad Mahajan \\ Associate Professor, (Orthopaedics) \\ Flat No. 12, Panchsheel Building, Sir J J Hospital Compound, Byculla, Mumbai 400008 \\ Email; mahajanneetinp@gmail.com
}

\begin{abstract}
Background- Surgeries around the hip joints are commonly found to have been associated with potential risk of immediate or late limb length inequality. Many times most of satisfaction level are associated with this problem. This study was performed in adults to determine the effects of shoe raise in significant limb equalities on patient satisfaction level on long basis.

Materials and Methods: We studied 112 patients attending Orthopaedics department of sir J J Group of Hospitals .with significant limb length inequalities following hip surgery around hip either due to trauma or replacement. Radiological analysis was done to calculate limb lenth difference. The gait analysis was done in 3 month interval till one year follow up. The patient satisfaction level analysis was done using harris hip score

Results: The gait pattern especially short limb gait was significantly improved following treatment with shoe raises. There was no significant improvement in muscular gaits like trendelen bergs gait or waddling gait. The patient satisfaction level was improved by 10 percent following shoe raises.

Conclusions: The treatment of limb length discrepancy using shoe raise has significant impact on patient satisfaction level especially symptomatic one. The shortening following trauma surgeries should be treated by shoe raises especially in cases of length or varus malunion.
\end{abstract}

Key Words- Limb Length discrepancy, Hip surgery, trauma and replacement, shoe raise.

\section{Introduction}

Hip surgeries are the commonly performed surgeries in any kind of orthopaedics speciality. Trauma around hip are the most indicated cause for surgeries, followed by arthroplasty, less followed by deformies corrections .Incidences of Hip surgeries have significantly increased in the present era due advances in principles of osteosynthesis as well as invention of different effective tools and implants for treating of intertrochanteric fractures, subtroch fractures, proximal femoral nonunions, hip arthritis, late presentations of instabilities around hip. The surgeries around the hips necessarily does not guarantee perfect anatomical reconstruction or restoration of normal biomechanics. The commonly listed complications around hip surgeries are malunion, non-union, dislocations, instability, gait abnormalities and the Leg-length discrepancy. 
The limb Length dyscripancy is well tolerated. Upto half inches of limb shortening is well compensated by the pevic tilt. Beyond that it significantly affects the outcome of surgery. This compensation around pevis reflects in compensation in lumber spine. The most cause for pain in back in long standing hip surgery cases. the previous limb length discrepancy has been associated with complications including nerve palsy, low back pain, and abnormal gait. Preoperative planning has the maximum role for reducing incidences of unaccepatable LLD. Careful preoperative measurement nd assessment, as well as preoperative and postoperative patient education, are important factors in achieving an acceptable result.H owever, after total hip arthroplasty, equal leg length should not be guaranteed. Rather, the patient should be given a realistic assessment of what can reasonably be expected.

High energy trauma around pelvis and hip regions are commonly associated with the pevic instability, acetabular fractures, proximal extrarticular fractures, subtochanteric fractures. The biggest challenge while treating communitted fracture aroung hip to get asymptomatic limb length inequality rather than union. Also Orthopaedicians have to compromise limb length Inequalities for achieving union. Majority of elderly population sustaining communited fractures like intertrochanteric or subtrochanterric fractures secondary to osteoporosis also are the victims of LLD and non satisfactory outcome.

Adventerous sportman and young adult populations of todays era are again more prone to heavy vehicular accidents. the communited fractures sustained are mostly treated with closed techniques. Secondary limb length dyscrepancy are well known. Most of them are responsible for non satisfactory outcomes.

Non unions and varus Malunions of neck region of femur are mostly associated with abductor relaxation, shortening and abductor force causing weakness of abductor and cause of trendelen berg's gait. Such symptomatic patients with multiple problems are mucjh less non satisfactory outcome.

The commonest cause of limb length Dyscrepancy in arthroplasty patients are neglected fracture neck femur for long duration, Hip excision arthroplasty, surgerired fir dysplasia around hip, perthes dises with coxa breva, sequelae of tom smith arthritis, Squelae of harmons procedures. Revision hip surgeries, the most common dissatisfaction rate amongst these patient are found to be associated with functional limitation following Thr. Same problems are associated with the Hemi replacement Surgery either with Bipolar or AMR. Next commom cause for LLD is osteotomies around proximal femur, The commonest indications are ganz osteotomy, Shanz osteotomy, Pelvic Support Osteotomy. These group of Patients are highly symptomatic.

Few group of people who do have LLD preoperatively and are sunjected to arthroplasty. The incidenceds of scaiatic nerve injury are common if attempted.

The commonest observation is the limb length dyscripancy are left untreated even though patients are not no satisfied with the surgical outcome. No attempts are made to address this problems.

The presence study is aimed at to note down prevalence of limb length Dyscrepancy following hip surgeries at our institute. The second objective was to study the outcome of treating LLD with shoe raise on satisfaction level of harris hip scores of these patients.

Also to assess relationship of preoperative radiologibcal preoperative planning on the final outcome of reducing LLD.

\section{Materials and Methods}

The study was carried out in State Government run Grant Medical College and Sir J J Group of Hospital ,Mumbai from 2013 to 2016 presenting to the department of Orthopaedics We reviewed the records of the Patients who have undergone surgery in our institute. The patients with LLD associated with symptomatic complains about 
Based on the intensions of our Study, We included all orthopaedic trauma, deformity correction, arthroplasty patients, treated with surgical intension and implants or prosthesis. Compound injuries grade I, closed diaphyseal and metaphyseal fractures, malunion, arthritis patients for Hip or knee replacement are included in the study designs. Patients with congenital problems like Proximal focal femoral deficiency, hemimelias, Ploytraumas, LLd less than $1.5 \mathrm{cms}$, Asympptoomatic LLDs are excluded ffrom study.

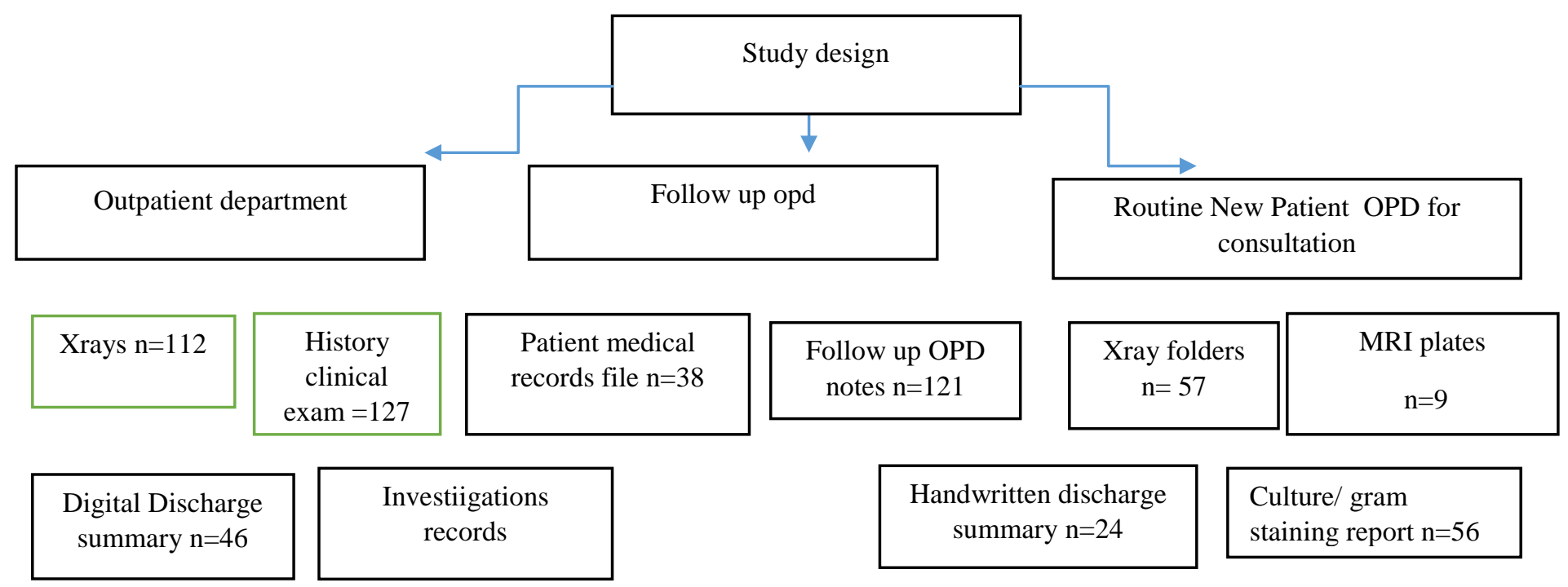

Figure 1. Schematic Diagram showing incusions of Patients for analysis

Source - OPD- patients concerned about LLdD / presented with LLd as the cause for Disability ? certification are included in the study protocol. First of they are clinically examined for Gait. three types of Gait are included for observation. Antalgic, short limb, trendelenberg, stigff spine Gait. Measurement of Apparent LLD and true LLD are taken. Apparent lengths are measured from xiphisternum to madialmalleolu. True lengtths are measured from anterior superior iliac spine to medial malleolus. On Evaluation of records, all Events are noted down on sheets as per proforma.

Harris Hip Score before treatment with Shoe Raise and follow up assessment done at 6 weeks , 3 months, 6 months, one year.

Deformities are noted down. Harris hip score is assessed,.

Radiographive evaluations done. Classification of injury done. The fractures are noted down/ Analysis started with two main groups. Study Group comprise of those patients significant shortening with concerns about surgery are treated with calculated shoe raises. Correction is also measured till correction off radiological tilt. Clinical squaring and radiological squaring are taken as criteria for equalising limb lengths.s operated in emergency deartments .

In our study, the common protocol was considered for all selected cases.

We studied the medical and radiological records of Examinations of 112 total patients 94 Males and 18 female patients and their mean follow up of one $\leq$ years . Xrays were analysied for diagnosis, type of injury, evidence of infection, cause of shortening, malunion, number of procedures done, treatment given for shortening. Analyses were made to find out the association between infection and risk factors, the v2 test was used. The strength of association of the single event with the variables was estimated using Relative Risk, with a $95 \%$ confidence interval and $\mathrm{P} \leq 0.05$.

\section{Results}

We studied 112 patients who were treated with orthopaedic surgeries and developed surgical site infection. 


\section{JMSCR VoI||05||Issue||08||Page 26444-26453||August}

Demographic and clinical characteristics of the study population are summarised in Table 1.

\begin{tabular}{|l|c|}
\hline Characteristics & Patient With LLD \\
\hline Age & $57.6 \pm 12.4$ \\
\hline Right : left & $50: 62$ \\
\hline Pelvic injuries Vertical instability & 2 \\
\hline Fracture neck femur & 23 \\
\hline Intertrochanteric fractures & 44 \\
\hline Subtrochanteric fracture & 45 \\
\hline Malunion /Nonunion & 2 \\
\hline Congenital problems & 6 \\
\hline Developmental Dysplasias & 2 \\
\hline Infections around hip & 12 \\
\hline Sequelae of Arthritis & 2 \\
\hline Instability post surgery & 12 \\
\hline Revision Hip surgeries & \\
\hline
\end{tabular}

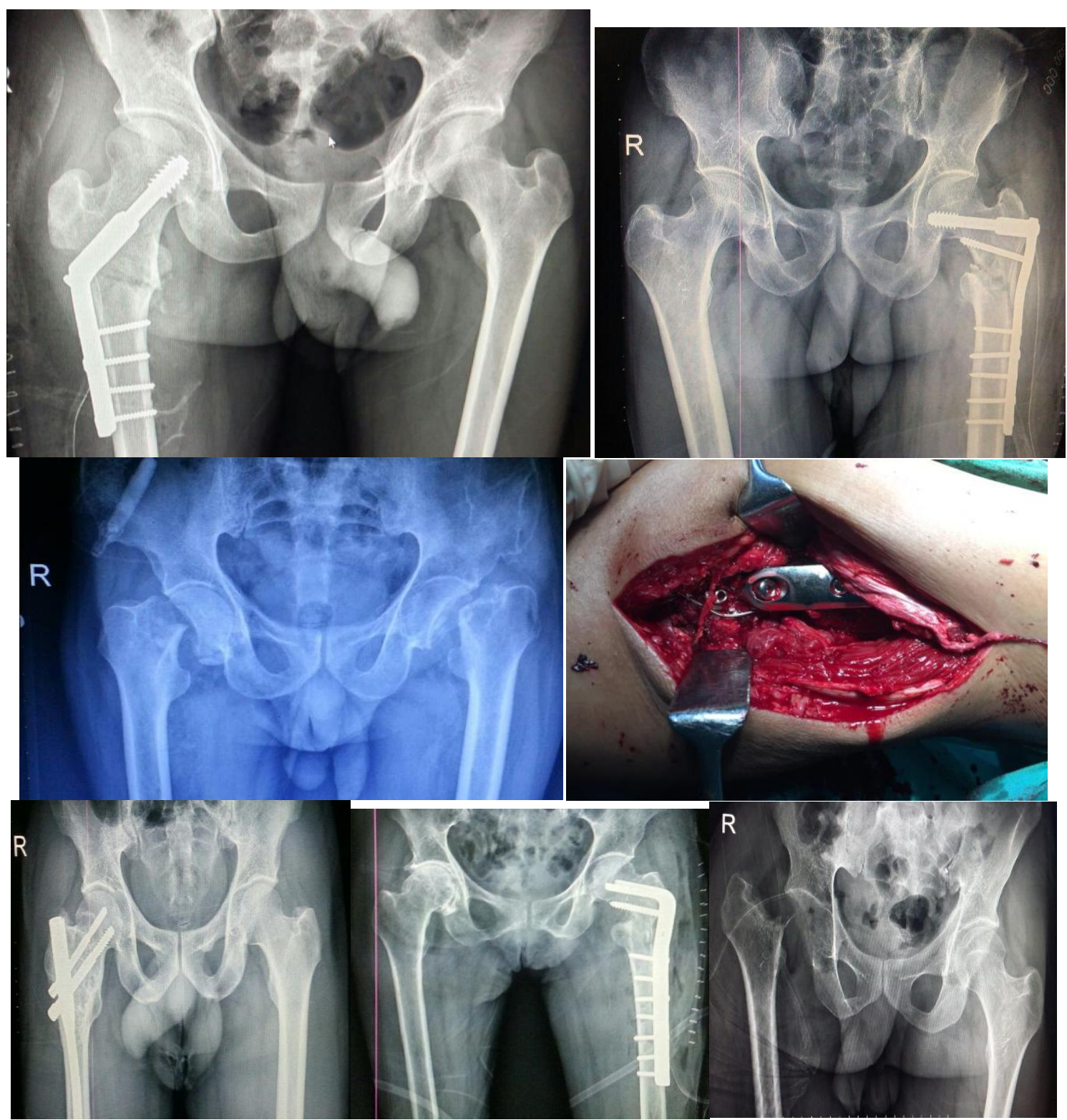


Table 2. showing Incidences of LLD after various Hip Surgeries

\begin{tabular}{|l|c|}
\hline Surgeries & LLD (number) \\
\hline Pelvis external fixation & 1 \\
\hline ORIF Sacral screws & 1 \\
\hline Acetabular fixation & 2 \\
\hline Ostetomy in Children & 5 \\
\hline Synovectomy / Biopsy & 7 \\
\hline Excision Arthroplasty & 12 \\
\hline Osteosynthesis Neck Femur & 1 \\
\hline Hemireplacement AMR & 13 \\
\hline Hemireplacement Bipolar & 16 \\
\hline Total Hip Replacement unilateral & 18 \\
\hline Total Hip Replacement Bilateral & 8 \\
\hline ORIF Intertrochanteric DHS & 12 \\
\hline ORIF Intertrochanteric PFN & 1 \\
\hline ORIF Subtrochanteric PFN & 6 \\
\hline ORIF Subtrochanteric DCS & 6 \\
\hline ORIFSubtrochanteric 95 angled Blade plate & 3 \\
\hline
\end{tabular}

Table 3. Distribution Of LLDs

\begin{tabular}{|l|c|c|}
\hline & Clinically measured true LLD & Radiologically measured True LLD \\
\hline $1.5 \mathrm{~cm}-2 \mathrm{~cm}$ & 21 & 22 \\
\hline $2 \mathrm{~cm}-2.5 \mathrm{~cm}$ & 24 & 34 \\
\hline $2.5 \mathrm{~cm}-3.0 \mathrm{cms}$ & 19 & 15 \\
\hline $3.0-3.5 \mathrm{~cm}$ & 26 & 17 \\
\hline $3.5-4 \mathrm{cms}$ & 11 & 12 \\
\hline $4-5 \mathrm{cms}$ & 5 & 7 \\
\hline $5-7.5 \mathrm{cms}$ & 5 & 5 \\
\hline Above $7.5 \mathrm{cms}$ & 1 & 1 \\
\hline
\end{tabular}

\begin{tabular}{|l|l|}
\hline Ages & Numbers \\
\hline $1-20$ yrs & 5 \\
\hline $20-30$ yrs & 25 \\
\hline $30-40 \mathrm{yrs}$ & 24 \\
\hline $40-50$ yrs & 15 \\
\hline $50-60$ yrs & 12 \\
\hline $60-70 \mathrm{yrs}$ & 25 \\
\hline $70-80 \mathrm{yrs}$ & 5 \\
\hline Above 80 yrs & 1 \\
\hline
\end{tabular}

In Our study, the prevalence of LLD was more common in trauma group . followed by hemirplacement with Bipolar, AMR and Subtrochanteric Group treated by plating and nailing

Previous LLD has been Seen to be progressed to some extent due to complication of Hemi replacement Arthroplasty.

These patients were subjected for periodical radiological and clinical monitoring by harris Hip score and Visual analogue Scale and and based on findings of harris hi score are analysed. Results are tabulated. Functional score base on Harris Hip Score is compared with LLD and after treatment / correction By shoe raise has been also notified.

Table 4. showing Clinical Profiles associated with LLD before and After Treatment with Shoe Raise

\begin{tabular}{|l|c|c|}
\hline \multirow{2}{*}{ Parameters } & \multicolumn{2}{|c|}{} \\
\cline { 2 - 3 } & With LLD & With Shoe RAise \\
\hline Low Back Pain & 34 & 14 \\
\hline Scoliotic List & 23 & 2 \\
\hline Hip pain & 15 & 8 \\
\hline Antalgic Gait & 7 & 7 \\
\hline Trendelenbergs Gait & 14 & 13 \\
\hline Short Limb Gait & 112 & 4 \\
\hline Knee pain & 11 & 2 \\
\hline Metatarsal pain & 12 & 2 \\
\hline
\end{tabular}




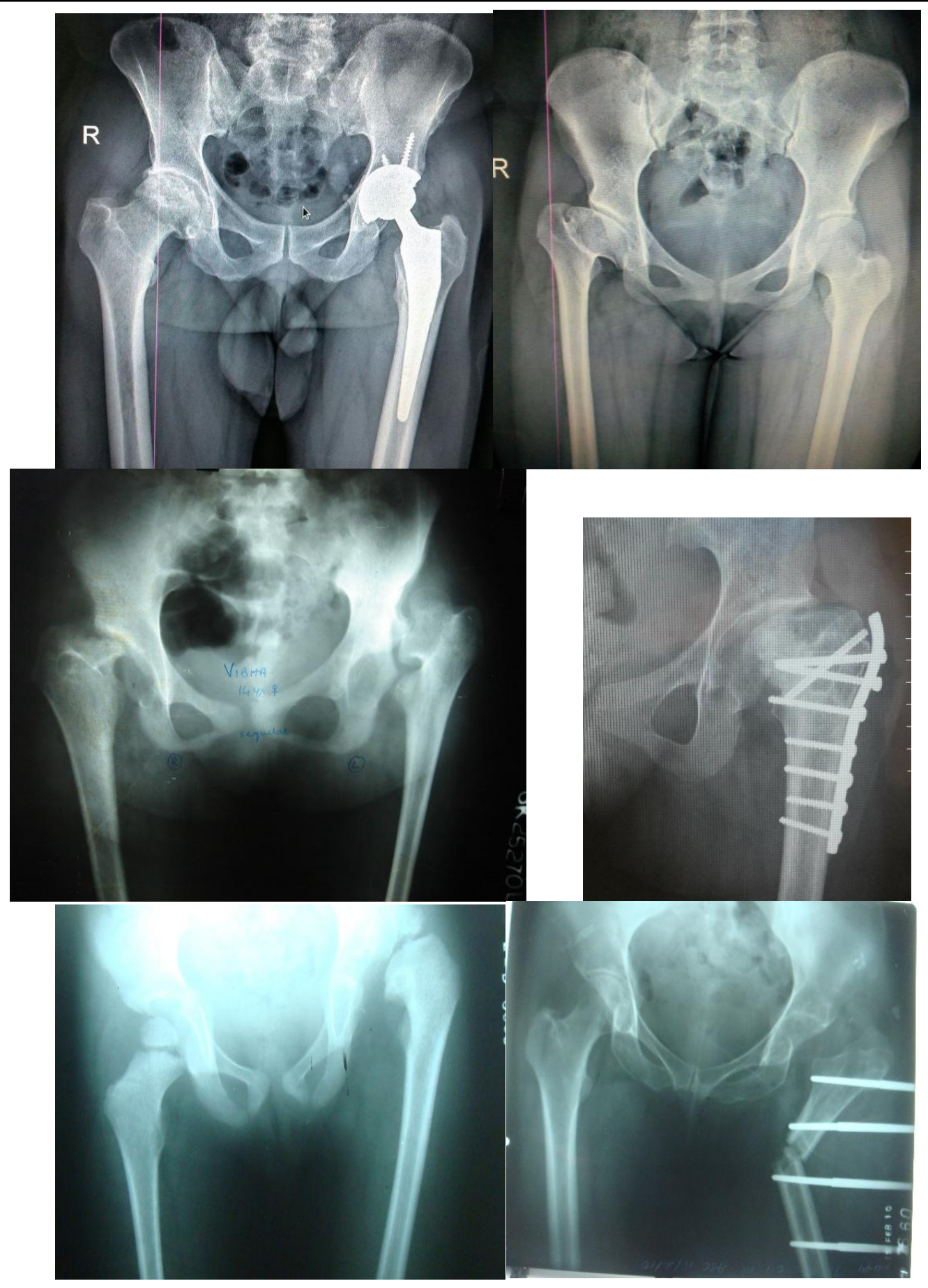

Figure 4 showing LLD following various surgeries around Hip

\begin{tabular}{|l|c|c|}
\hline Harris Hip score & With LLD & With Shoe Raise \\
\hline $80-100$ & 44 & 68 \\
\hline $60-80$ & 35 & 28 \\
\hline $40-60$ & 25 & 14 \\
\hline Less than 40 & 08 & 2 \\
\hline
\end{tabular}




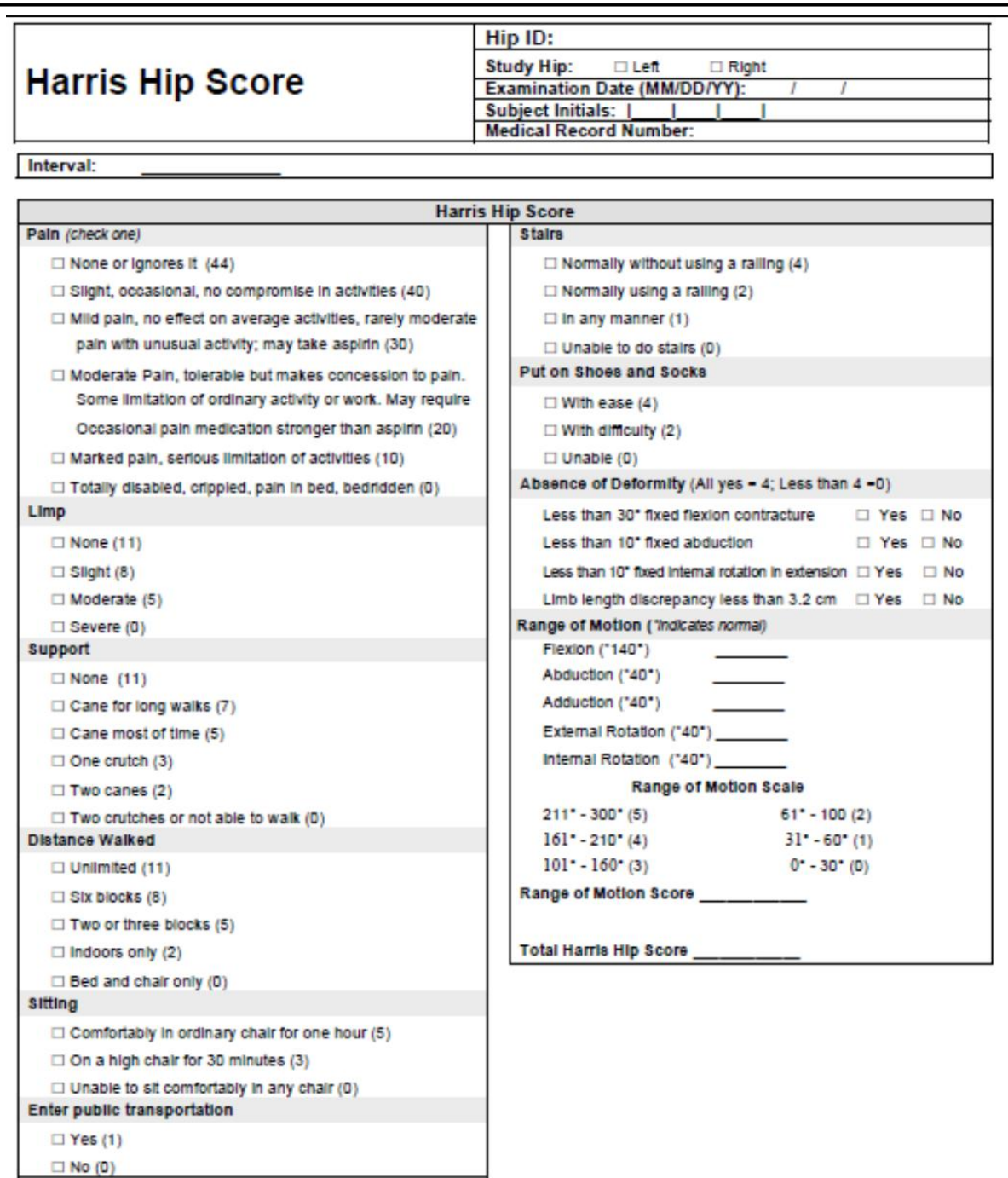

Diagram Showing Harris Hip Score

\section{Discussion}

Restoration of LLD is an important goal of any hip procedure whether it ia open reduction and internal fixation, deformity correction, synovial debridemnt or replacement, deformity corrections. Presence of Limb length Inequalities have been found to affect functional outcome. According to Rubash et al ${ }^{[26]}$ preoperative LLD of more than $2 \mathrm{~cm}$ presents social problems. They also allude that if shortening occurred in adult life, inequalities more than $2 \mathrm{~cm}$ may be attempted to correct and treat.

LLD has been perceived by $6 \%-32 \%$ of patients and universally perceived when shortening exceeds $10 \mathrm{~mm}$ and lengthening $6 \mathrm{~mm}$. Edeen et al stated that $32 \%$ of patients in their series were aware of LLD with an average LLD of $15 \mathrm{~mm}$.

Wylde et al also concluded that patients with LLD had significantly poorer HHS and limped more frequently. In contrast to all these studies, White and Dougall ${ }^{[25]}$, concluded that radiological lengthening up to $35 \mathrm{~mm}$ and shortening up to $21 \mathrm{~mm}$ following do not correlate with functional outcome of the patients (the authors used OHS and Harris Hip Scoring outcomes). However, the lack of correlation between LLD and functional outcome by using such surgeon based and generic tool, which lacks sensitivity and specificity of other disease-specific or joint-specific questionaires has been well criticized.

Various techniques have been described in the literature, which aims to avoid any LLD following THA. Preoperative templating seems an unreliable option as a done by using templating and a calliper device to overcome LLD, concluded that their technique is more accurate for patients with small preoperative LLD. 
Discrepancy of leg length is often considered to be a problem after replacement and can adversely affect an otherwise excellent outcome. Furthermore, it has been associated with patient dissatisfaction and remains one of the most common reasons for litigation against the orthopedic community. As a consequence of the need to equalize leg length, several authors have sought to validate methods of minimizing limb length discrepancy based on preoperative planning with preoperative radiological templates or intraoperative methods of measurement.

There is hardly any control on trauma surgeries to control on maintaining equality on limb lengths. Deformities have been also found to contribute to leg length inequalities. Hence we consider a attempt should be made to overcome bad functional outcome of dissatisfaction following hip surgeries by correcting the leg lengths. fact, there is a surprising amount of consensus in the literature regarding two key aspects of lower LLD; firstly, its ubiquitous nature and secondly, the threshold at which any intervention should be considered. It is also reassuring to know that this evidence derives from a wide variety of source In this article, we present a review of the limb length discrepancy following surgeries around hip for various intensions, we found out LLD alone is not a contributory factor for bad hipscore or dissatisfaction amongst LLD patient. But Correcting the LLD by external sources like shoe raise hasprofound impact in increasing the Harris Hip Scoore. But however it is not a sufficient treatment. Methods and techniques described for equalizing limb lengths should be followed to have good Harris Hip score following post op period.

Gait studies consistently show that a discrepancy less than $2 \mathrm{~cm}$ does not cause gait asymmetry, 3 nor are the kinematics or kinetics of gait altered significantly. ${ }^{4}$ The relationship between LLD and low back pain is less clear although the weight of opinion is again in favour of the proposition that LLD of less than $2 \mathrm{~cm}$ is not associated with any increase in the incidence of low back pain. ${ }^{5}$ Development of a scoliosis would not be unexpected, but it is difficult to explain why as many as one-third of reported curves are convex on the longer side. ${ }^{6}$ There is no evidence for increased incidence of hip or knee arthrosis for LLDs of $2 \mathrm{~cm}$ or less. ${ }^{7}$ In the words of Gross, ${ }^{1}$ "It is concluded that there seems little indication for equalisation of discrepancies less than $2 \mathrm{~cm}$. For larger amounts of discrepancy, "clinical judgment" still must be weighed on an individual basis, as individual variation among patients with leg length discrepancy confounds any precise classification of functional disability." Undoubtedly, the literature has proved that absolute equalization of limb length is difficult to achieve and LLD cannot be eliminated after Hip Surgeries IN OUR studies we have seen significant improvement in Short limb gait However there was no difference I correcting trendelenbergs gait or antalgic gait. Needed counselling and other modes of treatments for improving functional scores.

The excessive limb lengthening can also transform an excellent clinical result with respect to range of motion, pain relief, and function into a surgical failure because of patient dissatisfaction. Parvizi et al concluded that a marked postoperative LLD may lead to substantial disability as a result of pain or functional impairment, which warrants revision surgery

\section{Conclusions}

Based On observations In our Study, we can conclude that LLD is a common and recognized complication following surgeries around hip Joint mostly in trauma and Total hip replacement surgeries.. Therefore, it is paramount that surgeons maintain their focus on avoiding LLD as one of the primary goals of Total hip replacement and Open Reduction and internal fixation.T emplating to predict the necessary length correction and plan femoral neck osteotomy level and the intraoperative use of a simple pelvic reference pin with accuratere-positioning of the leg during measurements will provide the surgeon with a practical method for measuring leg length during Arthroplasty procedures. 
Heel Raises for leg length compensation will only be required for the short leg, i.e. in one sho if LLD is More than $15 \mathrm{~mm}$. This can make the two shoes fit and feel different, particularly if the heel lift adds cushioning in the shoe. Because leg length compensation will typically be needed permanently, long-term comfort and minimum stress on the foot is very important

Use of Shoe raise is a medical and personal decision, but it is strongly recommended that a health care professional be involved in the evaluation of the need and in monitoring the results. It cannot be used as a the gold standard method of treatment but for larger inequalities other surgical methods should be used to correct Limb length equalities

The treatment of limb Length Dyscrepancy has a significant impact on patient satisfaction level especially symptomatic one. The shortening followed by trauma surgeries should be treated by shoe raises if there are length or varus malunion of proximal femur.

\section{Conflicts of Interest - None}

\section{References}

1. Gross RH. Leg length discrepancy: how much is too much? Orthopedics 1978;1:307-10.

2. Knutson GA. Anatomic and functional leg-length inequality: a review and recommendation for clinical decisionmaking. Part I, anatomic leg-length inequality: prevalence, magnitude, effects and clinical significance. Chiropr Osteopat 2005;13:11.

3. Kaufman KR, Miller LS, Sutherland DH. Gait asymmetry in patients with limblength inequality.J Pediatr Orthop 1996; 16:144-50.

4. Goel A, Loudon J, Nazare A, et al.Joint moments in minor limb length discrepancy: a pilot study.Am J Orthop 1997;26:852-56.

5. Soukka A, Alaranta $H$, Tallroth $K$, et al. Leg-length inequality in people of working age. The association between mild inequality and low-back pain is questionable. Spine 1991;16:429-31.

6. Moseley CF. Leg length discrepancy. Pediatric Orthopaedics. Lovell WW, Winter RB (eds). Philadelphia, Lippincott Williams \& Wilkins, Fifth Edn, 2001:1107-08.

7. Stanitski DF. Limb length inequality: assessment and treatment options.J Am Acad Orthop Surg 1997;7:143-53.1. Ranawat CS, Rao RR, Rodriguez JA, Bhende HS. Correction of limb length inequality during total hip arthroplasty. J Arthroplasty. 2001;6:715-720. doi: 10.1054/arth.2001.24442.

8. Sayed-Noor AS, Hugo A, Sjoden GO, Wetenberg P. Leg length discrepancy in total hip arthroplasty: comparison of 2 methods of measurement. Int Orthop. 2009;33:189-193.

9. Clark CR, Huddleston HD, Schoch EP, Thomas BJ. Leg-length discrepancy after total hip arthroplasty. J Am Acad Orthop Surg. 2006;14:38-45.

10. Parvizi J, Sharkey PF, Bissett BA, Rothman RH, Hozack WJ. Surgical treatment of limb length discrepancy following total hip arthroplasty. J Bone Joint Surg Am. 2003;85:2310-2317.

11. Hofmann AA, Skrzynski MC. Leg length inequality and nerve palsy in total hip arthroplasty: a lawyer awaits! Orthopaedics. 2000;23:943-944.

12. Ranawat CS, Rodriguez JA. Functional leg-length inequality following total hip arthroplasty. J Arthroplast. 1997;12:359364. doi: 10.1016/S0883-5403(97)90190$\mathrm{X}$.

13. Sathappan SS, Ginat D, Patel V, Walsh M, Jaffe WL, Di Cesare PE. Effect of anaesthesia type on limb length discrepancy after total hip arthroplasty. J Arthroplast. 2008;23:203-209. doi: 10.1016/j.arth.2007.01.022. 
14. Turula KB, Frieberg O, Lindholm S, Tallroth K, Vankka E. Leg length inequality after total hip arthroplasty. Clin Orthop Relat Res. 1986;202:163-168.

15. Rand JA, Ilstrup DM. Comparison of Charnley and T-28 total hip arthroplasty. Clin Orthop Relat Res. 1983;180:201.

16. Frieberg O. Clinical symptoms and biomechanics of lumbar spine and hip joint in leg length inequality. Spine. 1983;8:643-651. doi: 10.1097/00007632198309000-00010.

17. Mihalko WM, Philips MJ, Krackow KA. Acute sciatic and femoral neuritis following total hip arthroplasty. J Bone Joint Surg Am. 2001;83:589-592.

18. Rosler J, Perka C. The effect of anatomical relationships on kinetic parameters after total hip replacement. Int Orthop. 2000;24:23-27. doi: $10.1007 / \mathrm{s} 002640050006$.

19. Ranawat CS. The pants too short, the leg too long! Orthopaedics. 1999;22:845-846.

20. Woo RYG, Morrey BF. Dislocations after total hip arthroplasty. J Bone Joint Surg Am. 1982;64:1295-1306.

21. Amstuz SM, Jinnah RH, Mail L. Revision of aseptic loose total hip arthroplasties. Clin Orthop Relat Res. 1982;170:21-33.

22. Austin MS, Hozack WJ, Sharkey PF, Rothman RH. Stability and leg length equality in total hip arthroplasty. J Arthroplast. 2003;18:88-90. doi: 10.1054/arth.2003.50073.

23. Love BRT, Wright K. Leg length discrepancy after total hip replacement. Proceedings of Australian Orthopaedic association. J Bone Joint Surg Br. 1983;65:103.

24. Williamson JA, Reckling FW. Limb length discrepancy and related problems following total hip replacement. Clin Orthop Relat Res. 1978;202:135-138.

25. Djerf K, Walshtrom O. Total hip replacement comparison between the Mckee-Farrar and Charnley prosthesis in a 5-year follow-up study. Arch Orthop Trauma Surg. 1986;105:158-162. doi: 10.1007/BF00433934.

26. Rubash HE, Parvataneni HK. The pants too short, the leg too long: leg length inequality after total hip arthroplasty. Orthopaedics. 2007;30:764-765. 